\title{
QUANTITATIVE PHYTOCHEMICAL ANALYSIS AND ANTIOXIDANT ACTIVITIES OF SOME CITRUS FRUITS OF SOUTH INDIA
}

\author{
PALLAVI M ${ }^{1}$, RAMESH CK ${ }^{1 *}$, KRISHNA V ${ }^{2}$, SAMEERA PARVEEN ${ }^{1}$, NANJUNDA SWAMY L ${ }^{3}$ \\ ${ }^{1}$ Post-graduate Department of Studies and Research in Biotechnology, Molecular Biomedicine Laboratory, Sahyadri Science College, \\ Kuvempu University, Shimoga, Karnataka, India. ${ }^{2}$ Post-graduate Department of Studies and Research in Biotechnology and Bioinformatics, \\ Jnana Sahyadri, Kuvempu University, Shimoga, Karnataka, India. ${ }^{3}$ Department of Academic Staff College, University of Mysore, Manasa \\ Gangothri, Mysore, Karnataka, India. Email: ckramck@gmail.com
}

Received: 23 June 2017, Revised and Accepted: 29 October 2017

\section{ABSTRACT}

Objective: The current investigation was contemplated to evaluate the phytochemicals and in vitro antioxidant activities in peel and pulp of some commercially grown citrus fruits of South India, namely, lemon (Citrus aurantifolia), orange (Citrus reticulata), sour orange (Citrus aurantium), pomello (Citrus grandis), and citron (Citrus medica).

Methods: The peel and pulp of the fruits were separated and subjected to cold extraction using $70 \%$ alcohol. The extracts obtained were screened for the presence of their phytoconstituents using various qualitative and further quantified for major constituents. Further, the in vitro antioxidant activity was assayed by different radical scavenging methods, namely, 2,2-diphenyl-1-picrylhydrazyl, superoxide anion, nitric oxide, lipid peroxidation inhibition, iron chelating activity, and reducing power assay at different concentrations.

Results: All the citrus fruits have shown significant in vitro antioxidant activity for the parameters assessed, wherein peel extracts recorded superior antioxidant potential than their corresponding pulps. The broad range of activity of the extracts suggests that multiple mechanisms mediated by the phytoconstituents are responsible for the antioxidant activity.

Conclusion: The study thus revealed that peel and pulp of citrus fruits are potential sources of bioactive compounds which are reflected in antioxidant activity and supports their health-promoting claims of plethora of investigations.

Keywords: Citrus fruits, Peel, Pulp, Qualitative and quantitative, In vitro antioxidant activity.

(C) 2017 The Authors. Published by Innovare Academic Sciences Pvt Ltd. This is an open access article under the CC BY license (http://creativecommons. org/licenses/by/4. 0/) DOI: http://dx.doi.org/10.22159/ajpcr.2017.v10i12.20912

\section{INTRODUCTION}

Oxygen being an obligatory element of life, living systems have evolved to survive in the presence of molecular oxygen and for most biological systems [1]. Many of the harmful effects of oxygen are ascribed to the formation and activity of reactive oxygen species (ROS) behaving as oxidants, which have a tendency to donate oxygen to other substances. Most of the ROS are free radicals and are extremely reactive and short lived [2]. Free radicals occur continuously in all cells as part of normal metabolism. At low concentration, some of the free radicals offer positive physiological effect in vivo, and this includes defense against infectious agents by phagocytosis, energy production, cell growth, function in different cellular signaling systems, and the induction of a mitogenic response [1]. On the other hand, these free radicals are detrimental to the integrity of biological tissue and mediate their injury. The mechanism of damage involves lipid peroxidation (LPO), which destroys cell structures, lipids, proteins, and nucleic acids [3,4]. The human body has an array of mechanisms, especially enzymatic and non-enzymatic antioxidant systems, to protect cells and their constituents against ROS and free radical-induced damage [5].

Oxidative stress is a condition which occurs due to imbalance between free radicals and antioxidant defense system. Oxidative stress plays an important contributory role in the process of aging and pathogenesis of numerous diseases such as diabetes, cancer, neurodegenerative diseases, and respiratory tract disorder [5-7]. To counteract oxidative stress, the body produces an armory of antioxidants to defend itself. It is the role of antioxidants to neutralize or clear free radicals that can affect the cells. The body's internal production of antioxidants is not enough to neutralize all the free radicals. The body can be helped to defend itself by increasing dietary intake of antioxidants [8].

Antioxidants are the substances, compounds, or nutrients in our foods which can prevent or slow oxidative damage to our bodies. These agents are able to antagonize the deleterious effects of free radicals within our body [9]. Recent investigations have shown that the antioxidants of plant origin with free-radical scavenging properties could be useful as therapeutic agents in several diseases caused due to oxidative stress [10]. Many synthetic antioxidant compounds have shown toxic and/or mutagenic effects, which have stimulated the interest of many investigators to search natural antioxidant $[1,11]$. Natural products, mainly obtained from dietary sources, provide a large number of antioxidants. It is increasingly being accepted that fruits and vegetables have many health-promoting properties [12], and the consumption of fruit juices, beverages, and hot drinks has been showed to be inversely associated with morbidity and mortality from degenerative diseases [9].

The genus Citrus, which belongs to the family of Rutaceae, is rich genera of edible fruits of various species, and they are one of the main fruit tree crops grown worldwide. Citrus fruits have long been valued as part of a nutritious and tasty diet. Citrus and their products are a rich source of vitamins, minerals, and dietary fiber that are essential for normal growth and development and overall nutritional well-being. Fruits are used raw, pickled, and are esteemed for desert, made into jams and marmalades. Many Citrus species are recognized for their medicinal, physiological, and pharmacological activities including antimicrobial, antioxidant, anticancer, anti-inflammatory, and hypoglycemic activities [13]. The health benefits of Citrus fruit 
have been attributed to the presence of bioactive compounds, such as phenolics (e.g., flavanone glycosides and hydroxylcinnamic acids), Vitamin C, and carotenoids [14]. Ascorbic acid is the most important antioxidant in Citrus fruit juices, and it protects the organism from oxidative stress. Flavanones, flavones, and flavonols are three types of flavonoids which occur in Citrus fruit [9].

In view of huge importance of Citrus fruits as antioxidant sources, in the present research, a comparison of their antioxidant property of commonly consumed Citrus fruits of South India was investigated to evaluate their extent antioxidant potential. Antioxidant molecules such as phenolics, ascorbic acid, and flavonoids were also quantified to understand their contribution to the overall bioactive principles.

\section{METHODS}

\section{Collection of plant materials}

The Citrus fruits were procured from a local market of Shimoga, Karnataka, which were authenticated by the Taxonomist, Department of Botany, Sahyadri Science College, Shimoga. The fruits selected include lemon (Citrus aurantifolia), orange (Citrus reticulata), sour orange (Citrus aurantium), pomello (Citrus grandis), and Citron (Citrus medica) (Fig. 1). After selection, fruits were washed under running tap water followed by washing with distilled water to remove the surface debris. Then, the peel and pulp of the fruits were separated and were further subjected for extraction procedures.

\section{Extraction}

Exactly $1000 \mathrm{~g}$ of the separated peel and pulp were subjected to extraction procedure using 70\% ethanol as per the method described by Jamuna et al. 2015 [15], and the yield of the extract was calculated.

\section{Qualitative phytochemical analysis}

The phytochemical screening was performed for testing the different chemical groups present in ethanolic extracts of both peel and pulp of all Citrus fruits [16-18].

\section{Quantitative phytochemical analysis}

\section{Total phenolic content}

The total phenolic content was estimated according to the method of Chandler and Dodds, 1993 [19], and the results were expressed as gallic acid equivalent in $\mu \mathrm{g} / \mathrm{mg}$ of extract.

\section{Total flavonoid content}

A total flavonoid content of all the extracts was determined by the method of Zhishen et al. 1999 [20], and the values were expressed as catechol equivalent in $\mu \mathrm{g} / \mathrm{mg}$ of extract.

\section{Ascorbic acid content}

Ascorbic acid content of peel and pulp extracts of Citrus was determined by 2,4-dinitrophenylhydrazine method as described by Sadasivam and
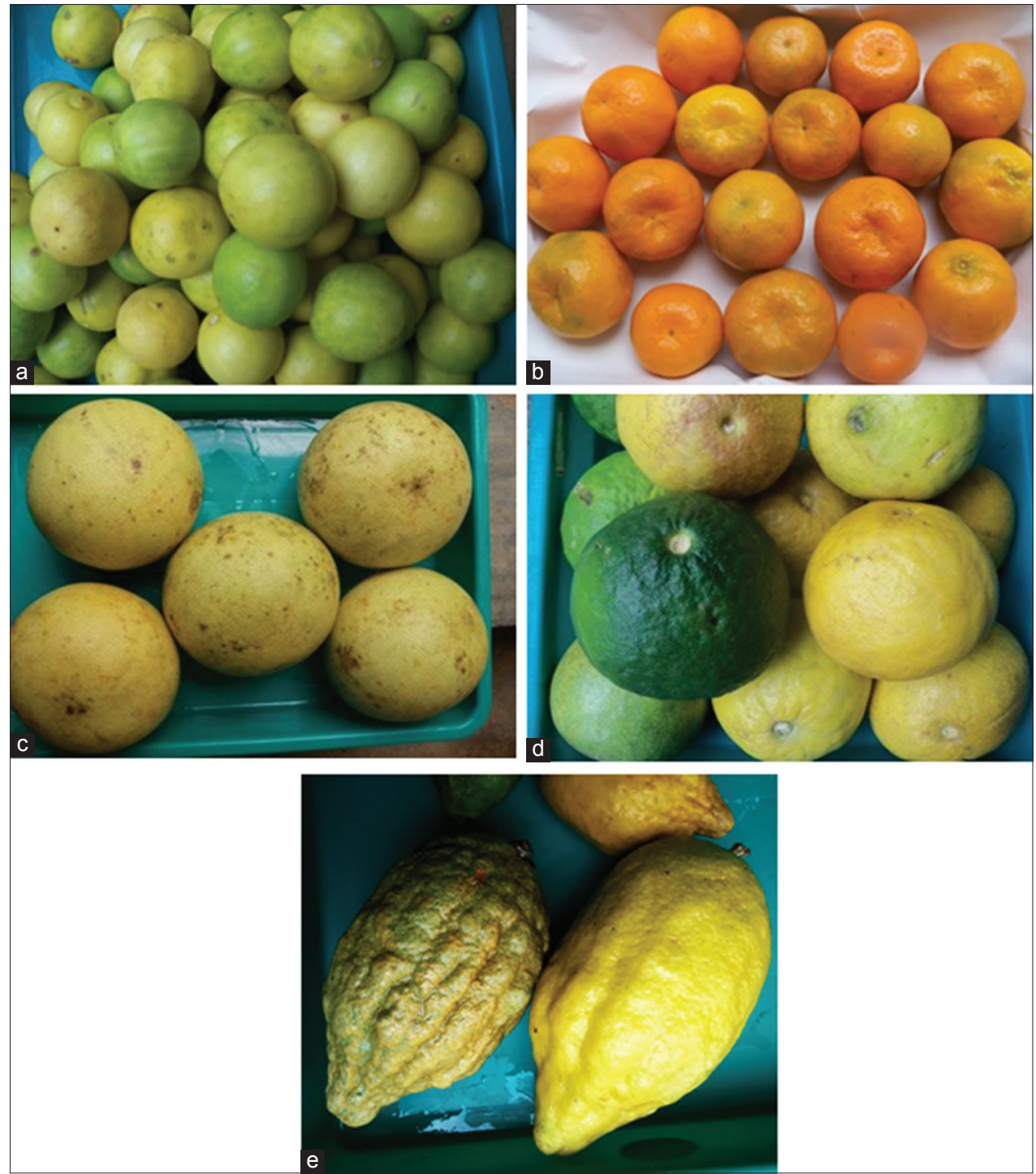

Fig. 1: Citrus fruits. (a) Citrus aurantifolia. (b) Citrus reticulate. (c) Citrus grandis. (d) Citrus aurantium and (e) Citrus medica 
Manickam, 2004 [21], and the results were expressed as ascorbic acid equivalents in $\mu \mathrm{g}$.

\section{Total antioxidant capacity (TAC)}

The TAC of all the ten extracts was performed according to the procedure of Prieto et al. 1999 [22]. The TAC of each extract is expressed as equivalents of ascorbic acid in $\mu \mathrm{g} / \mathrm{mg}$ of extract.

\section{Evaluation for in vitro antioxidant activities}

2,2-diphenyl-1-picrylhydrazyl (DPPH) radical scavenging activity DPPH free radical scavenging assay was measured using DPPH free radical test, by employing the method of Wong et al. 2006 [23]. DPPH radical scavenging activity of butylated hydroxytoluene (BHT) was assayed for comparison. Free radical scavenging activity was expressed as inhibition percentage and was calculated using the following formula. The results are expressed as half maximal effective concentration $\left(\mathrm{EC}_{50}\right)$, which is the amount of antioxidants necessary to decrease the initial concentration by $50 \%$.

Percentage effect $(E \%)=\left(A_{0}-A_{1}\right) / A_{0} \times 100$

Where $A_{0}$ is the absorbance of the control (without test samples), and $A_{1}$ is the absorbance of test samples.

\section{Nitric oxide radical scavenging activity}

Nitric oxide radical scavenging activity was determined according to the method reported by Garrat, 1964 [24]. BHT was used as positive control, and the results are expressed as $\mathrm{EC}_{50}$.

\section{Ferrous ion $\left(\mathrm{Fe}^{2+}\right)$ chelating activity}

The chelation of ferrous ions by extracts was estimated by the method of Dinis et al. 1994 [25]. Ethylenediaminetetraacetic acid was used as a standard metal chelating agent, and the results are expressed as $\mathrm{EC}_{50}$.

\section{Superoxide anion radical scavenging assay}

Superoxide anion radical scavenging activity of all the extracts was determined using the slight modified version of Nishimiki et al. 1972 [26]. BHT was used as a standard, and percentage of inhibition was calculated and expressed as $\mathrm{EC}_{50}$.

\section{Reducing power assay}

Total reduction capability of extracts was estimated using the method of Oyaizu [27]. Increase in absorbance of the reaction mixture indicates increased reducing power. $\mathrm{EC}_{50}$ value ( $\mu \mathrm{g}$ of extract $/ \mathrm{ml}$ ) is the effective concentration at which the absorbance was 0.5 for reducing power. Ascorbic acid was used as a standard.

\section{LPO inhibition assay}

Thiobarbituric acid reacts with malondialdehyde to form a diadduct, a pink chromogen, which can be detected as per the method of Halliwell and Guttridge [28]. Percentage of inhibition was expressed as $\mathrm{EC}_{50^{\circ}}$

\section{Statistical analysis}

All the experiments were carried out in triplicates. The result of the triplicates was pooled and expressed as mean \pm standard error.

\section{RESULTS}

\section{Extraction yield}

Ethanolic extract of both peel and pulp of all the five Citrus fruits was weighed, and the yields obtained were noted. In case of peel extracts, orange showed highest yield (89.43 g), followed by pomello (86.82 g), citron (72.15 g), lemon (54.18 g), and sour orange (48.86 g), whereas in pulp extracts, pomello revealed high percentage of yield $(92.27 \mathrm{~g})$, followed by orange (91.70 g), lemon (80.86 g), sour orange (68.36 g), and citron $(58.97 \mathrm{~g}$ ) per $\mathrm{kg}$ of the fruit material (Table 1).
Table 1: Yield of peel and pulp extracts of five Citrus fruits

\begin{tabular}{lll}
\hline Name of the fruit & \multicolumn{2}{l}{ Yield $(\mathrm{g})$} \\
\cline { 2 - 3 } & Peel extracts & Pulp extracts \\
\hline Lemon & 54.18 & 80.86 \\
Orange & 89.43 & 91.70 \\
Sour orange & 48.86 & 68.36 \\
Pomello & 86.82 & 92.27 \\
Citron & 72.15 & 58.97 \\
\hline
\end{tabular}

\section{Qualitative phytochemical analysis}

The preliminary qualitative phytochemical investigation documented that the peel and pulp extracts of all five Citrus fruits showed the presence of many bioactive compounds, namely, polyphenols, flavonoids, terpenoids, steroids, glycosides, alkaloids, and carotenoids. The results also revealed that saponins were present in both peel and pulp extracts of orange and citron and in peel extract of sour orange, whereas absent in both peel and pulp extracts of lemon and pomello. The results of the analysis are shown in Table 2.

\section{Quantitative phytochemical analysis}

\section{Total phenolic content}

The amount of total phenolic contents was present in varying concentrations in the different extracts of Citrus fruits. The results were expressed as the number of equivalents of gallic acid ( $\mu \mathrm{g} / \mathrm{mg}$ of extract) and were found to be highest in citron peel (66.36) and pulp (51.21), followed by peel extracts of orange (48.5), lemon (46.65), sour orange (41.5), and pomello (40.14). While the pulp extracts of orange, lemon, sour orange, and pomello recorded 28.34, 34.26, 37.72, and $21.39 \mu \mathrm{g}$, respectively (Fig. 2a).

\section{Total flavonoid content}

The standard curve of catechol was used to express the total flavonoid content of the peel and pulp extracts of Citrus fruits and was expressed in terms of catechol equivalence $(\mu \mathrm{g} / \mathrm{mg}$ of extract). The results revealed that citron peel and pulp extracts have maximum content of total flavonoids (40.17 and 37.9), followed by sour orange (39.23 and 29.83), lemon (36.49 and 15.19), pomello (28.11 and 30.22), and orange (21.61 and $20.75 \mu \mathrm{g}$ ) (Fig. 2b), respectively.

\section{Total ascorbic acid content}

Standard ascorbic acid was used to express the ascorbic acid content of the fruit extracts and was expressed in terms of ascorbic acid equivalence in $\mu \mathrm{g} / \mathrm{mg}$ of extract. From the results, it is evident that orange peel extract has maximum content of ascorbic acid (52.67), followed by citron (33.77), pomello (30.81), sour orange (27.21), and lemon peel extracts (20.21), whereas pulp extracts showed orange (25.9), lemon (24.87), citron (24.69), sour orange (24.09), and pomello $(23.93 \mu \mathrm{g})$ of ascorbic acid (Fig. 2c)

TAC

The results of TAC revealed that all Citrus fruit extracts under the study possess significant antioxidant potential (Fig. $2 \mathrm{~d}$ ). The results were compared with the standard curve of ascorbic acid and were expressed in terms of the equivalence of ascorbic acid in $\mu \mathrm{g} / \mathrm{mg}$ of extract. From the results, it was found that citron peel and pulp extracts showed the maximum content of total antioxidants (140.17 and 116.11), followed by lemon (125 and 59.04), sour orange (123.77 and 53.02), orange (109.53 and 74.71), and pomello (98.91 and $87.64 \mu \mathrm{g}$ ), respectively.

\section{Evaluation for in vitro antioxidant activities}

DPPH radical scavenging activity

DPPH radical scavenging activity of the different extracts at varying concentrations was measured along with $\mathrm{BHT}^{\text {. The }} \mathrm{EC}_{50}$ values for fruit extracts were found to be highest in citron peel $(827.26 \mu \mathrm{g} / \mathrm{ml})$, followed 

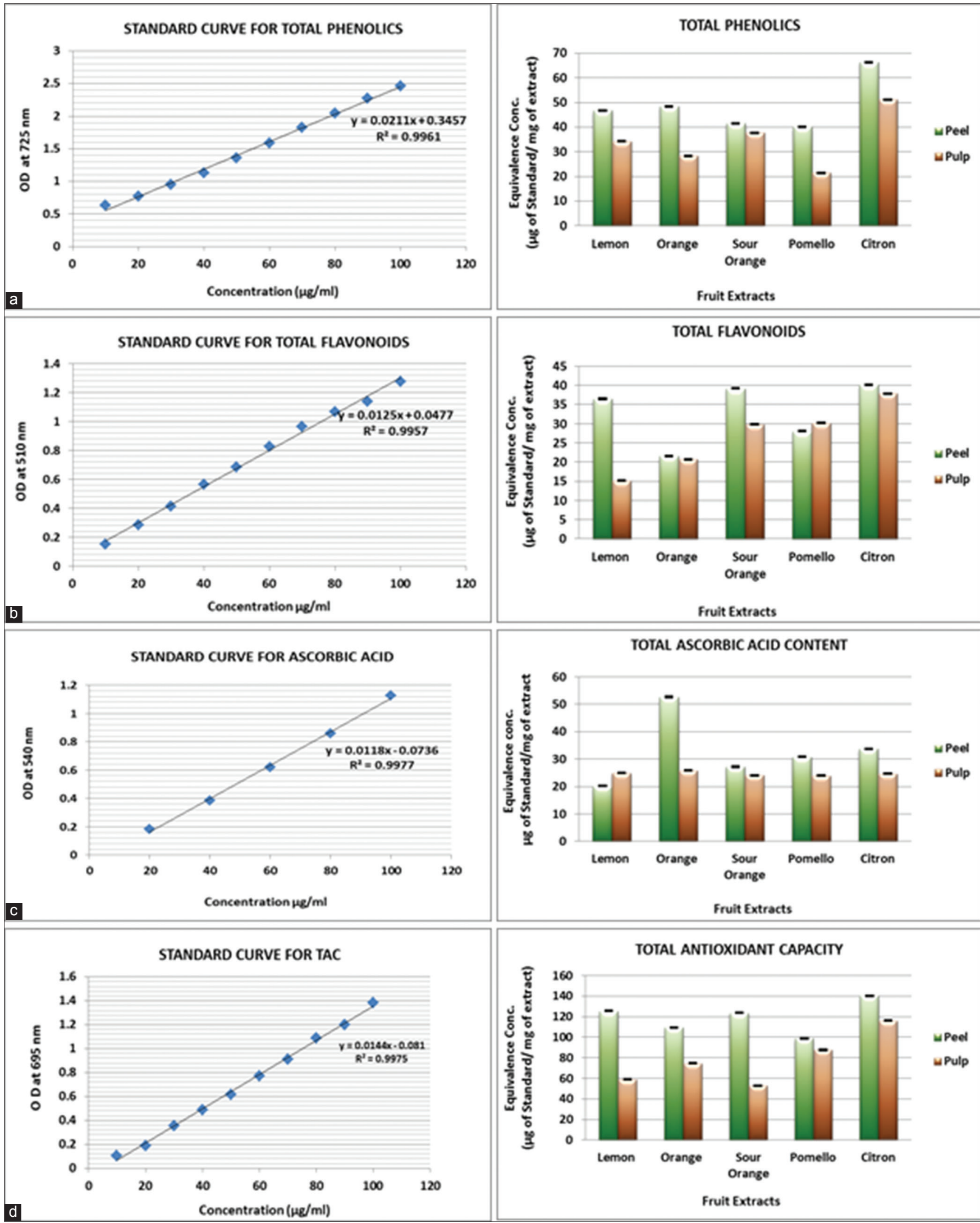

Fig. 2: Quantitative phytochemical evaluation of five Citrus fruits (a) standard curves and equivalence of total phenolics (b) standard curves and equivalence of total flavonoids (c) standard curve and equivalence of total ascorbic acid content (d) standard curve and equivalence of total antioxidant capacity

by peel extracts of lemon $(977.89 \mu \mathrm{g} / \mathrm{ml})$, orange $(1097.45 \mu \mathrm{g} / \mathrm{ml})$, sour orange $(1213.29 \mu \mathrm{g} / \mathrm{ml})$, and pomello $(1485.88 \mu \mathrm{g} / \mathrm{ml})$. While the pulp extracts of orange, citron, lemon, sour orange, and pomello showed $\mathrm{EC}_{50}$ values of $3628.44,4089.64,4184,5006$, and $5464.48 \mu \mathrm{g} / \mathrm{ml}$, 
Table 2: Qualitative phytochemical analysis of five Citrus fruits

\begin{tabular}{|c|c|c|c|c|c|c|c|c|c|c|}
\hline \multirow[t]{2}{*}{ Tests } & \multicolumn{2}{|c|}{ Lemon } & \multicolumn{2}{|c|}{ Orange } & \multicolumn{2}{|c|}{ Sour orange } & \multicolumn{2}{|c|}{ Pomello } & \multicolumn{2}{|c|}{ Citron } \\
\hline & Peel & Pulp & Peel & Pulp & Peel & Pulp & Peel & Pulp & Peel & Pulp \\
\hline Steroids & + & + & + & + & + & + & + & + & + & + \\
\hline Glycosides & + & + & + & + & + & + & + & + & + & + \\
\hline Terpenoids & + & + & + & + & + & + & + & + & + & + \\
\hline Saponins & - & - & + & + & + & - & - & - & + & + \\
\hline Alkaloids & + & + & + & + & + & + & + & + & + & + \\
\hline Carotenoids & + & + & + & + & + & + & + & + & + & + \\
\hline Flavonoids & + & + & + & + & + & + & + & + & + & + \\
\hline Tannins and polyphenols & + & + & + & + & + & + & + & + & + & + \\
\hline
\end{tabular}

respectively. Whereas BHT has registered an $\mathrm{EC}_{50}$ value of $65.75 \mu \mathrm{g} / \mathrm{ml}$ (Fig. 3a). The results demonstrated the dose-dependent DPPH radical scavenging activity in terms of $\mathrm{EC}_{50}$.

\section{Nitric oxide radical scavenging activity}

All the ten extracts of Citrus fruits showed significant activity in competing with oxygen to react with nitric oxide and thus the inhibition of anions. The results of nitric oxide radical scavenging activity revealed that orange pulp extract possessed better scavenging effect than other peel and pulp extracts. The peel and pulp extracts of lemon, orange, sour orange, pomello, and citron recorded $\mathrm{EC}_{50}$ values of 761.84 and 856.16, 899.76 and 727.06, 823.85 and 792.64, 917.93 and 799.1, and 871.68 and $878.88 \mu \mathrm{g} / \mathrm{ml}$, respectively (Fig. 3b).

\section{Ferrous ion $\left(\mathrm{Fe}^{2+}\right)$ chelating activity}

The peel extracts of sour orange and lemon possessed potent iron chelating activity with $\mathrm{EC}_{50}$ values of 827.95 and $871.08 \mu \mathrm{g} / \mathrm{ml}$, respectively, followed by pomello $(1193.03 \mu \mathrm{g} / \mathrm{ml})$ and orange $(1478.41 \mu \mathrm{g} / \mathrm{ml})$ extracts. Among the pulp extracts, orange $(1052.18 \mu \mathrm{g} / \mathrm{ml})$ showed better activity than lemon $(1145.73 \mu \mathrm{g} / \mathrm{ml})$, sour orange $(1257.54 \mu \mathrm{g} / \mathrm{ml})$, and pomello $(1864.97 \mu \mathrm{g} / \mathrm{ml})$. While in both the peel and pulp extracts of citron, iron chelating activity was not noticeable (Fig. 3c)

\section{Superoxide radical scavenging assay}

The superoxide anion radical scavenging activity of the different extracts from peel and pulp of Citrus fruits assayed by the phenazine methosulfate/NADH system and their $\mathrm{EC}_{50}$ values were depicted in Fig. 3d. The results infer that $\mathrm{EC}_{50}$ values for test extracts were found to be highest in sour orange peel, followed by peel of citron $(2228.165 \mu \mathrm{g} / \mathrm{ml})$, pomello $(2252.255 \mu \mathrm{g} / \mathrm{ml})$, orange $(2335.575 \mu \mathrm{g} / \mathrm{ml})$, and lemon $(2447.625 \mu \mathrm{g} / \mathrm{ml})$. In pulp extracts, citron showed better activity with $\mathrm{EC}_{50}$ value of $2621.09 \mu \mathrm{g} / \mathrm{ml}$, followed by orange (2629.91), lemon (2657.87), sour orange (2763.65), and pomello (2969.12 $\mu \mathrm{g} / \mathrm{ml})$. The standard BHT showed 50\% inhibition at $49.19 \mu \mathrm{g} / \mathrm{ml}$.

\section{Reducing power assay}

The reducing capacity of a compound may serve as an important indicator of its potential antioxidant activity. All the fruit extracts have shown prominent reducing power effect in dose-dependent manner and were found to be high in lemon peel extract with an effective concentration of $170.94 \mu \mathrm{g} / \mathrm{ml}$, followed by peel extracts of citron (276.62), pomello (365.63), orange (497.51), and sour orange (750.46), whereas pulp extracts of pomello, orange, citron, sour orange, and lemon exhibited an $\mathrm{EC}_{50}$ value of 725.95, 877.19, 917.43, 1123.59, and $1412.42 \mu \mathrm{g} / \mathrm{ml}$, respectively (Fig. 3e).

\section{LPO inhibition assay}

The LPO inhibition assay of extracts of five Citrus fruits was investigated in comparison with the known antioxidant butylated hydroxylanisole (BHA). The peel and pulp extracts of orange fruit had higher LPO inhibition in mice liver with $\mathrm{EC}_{50}$ values 883.7 and $946.61 \mu \mathrm{g} / \mathrm{ml}$, respectively. The $\mathrm{EC}_{50}$ values of inhibition of LPO activity in peel and pulp extracts of lemon, citron, pomello, and sour orange was found to be 928.85 and $957.12 \mu \mathrm{g} / \mathrm{ml}, 931.27$ and $951.83 \mu \mathrm{g} / \mathrm{ml}, 936.32$ and $981.54 \mu \mathrm{g} / \mathrm{ml}$, and 944.1 and $990.09 \mu \mathrm{g} / \mathrm{ml}$, respectively. The standard BHA recorded $\mathrm{EC}_{50}$ values of $172.11 \mu \mathrm{g} / \mathrm{ml}$ (Fig. 3f).

\section{DISCUSSION}

Fruits are dietetically prominent component of foodstuffs. It has been documented that fruit and vegetables are important parts of a diseasepreventing diet. The results of the recent research clearly indicate the importance of fruit and vegetables as the richest potential source of antioxidants and emphasize the need to increase the proportion of these products in the diet $[29,30]$. The consumption of fruits has been inversely linked with morbidity and mortality from degenerative diseases [31-33]. It is not known which dietary constituents are responsible for this association, but antioxidants seem to play the crucial function in the protective functions of plant foods [32-35].

In the present study, peel and pulp of five different Citrus fruits, namely, lemon, orange, sour orange, pomello, and citron commonly cultivated in South India were tested for different phytoconstituents. The result of qualitative phytochemical analysis documented that all the ten extracts of Citrus fruits are bestowed with the presence of several bioactive compounds, namely, polyphenols, flavonoids, terpenoids, steroids, glycosides, alkaloids, and carotenoids. In the recent years, there is an increasing interest in finding antioxidants of natural origin. The most effective antioxidants are flavonoids, and other phenolic compounds present in plants particularly in herbs, seeds, and fruits [36,37]. Okwu and Emenike 2007 screened phytochemicals of five Citrus species and revealed the presence of saponins, tannins, flavonoids, alkaloids, and phenols. Further, the results of quantitative estimation revealed the presence of higher concentration of several potential antioxidant components such as total phenols, flavonoids, ascorbic acid, and total antioxidants in Citrus peel extracts than the pulp extracts [38]. Phenolics in fruits and vegetables, as well as Vitamin C, are said to be effective antioxidants. Both juice and peel contain nutraceuticals; nevertheless, it has been demonstrated that they are more abundant in Citrus peel [39-41]. The results of the present investigation, therefore, are in accordance with others who indicated that peels are an important source of phenolics $[42,43]$.

In the recent years, potent free radical scavengers have attracted a huge interest as possible therapeutics against free radical-mediated diseases [44]. Natural compounds show stronger antioxidant activity which is likely to quench free radicals. The antioxidant activity may act in various ways by scavenging the radicals, decomposing peroxides, and chelating metal ions [45]. Frankel and Kolevaet suggested that the use of different methods is necessary in antioxidant activity assessment to understand the various antioxidation mechanisms which are operating in the cellular system [46-48]. In the present study, the antioxidant potentials of five Citrus fruits peel and pulp extracts were assessed using various in vitro assays at different concentrations. From the results, it was observed that all the Citrus fruit extracts manifested potent antioxidant activities. For all Citrus fruits, peels gave pronounced 

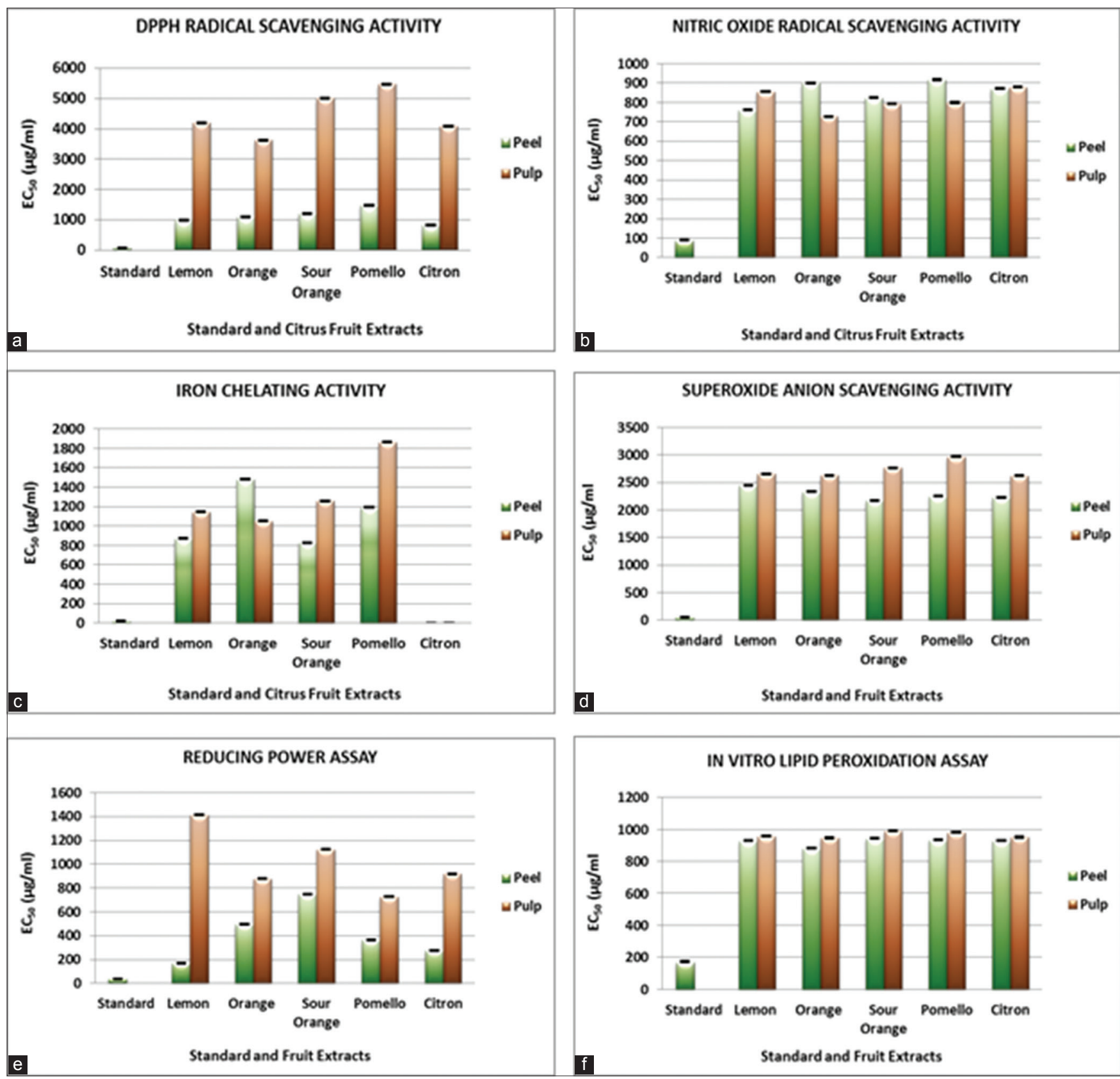

Fig. 3: In vitro antioxidant activities (half maximal effective concentration) of five Citrus fruit extracts (a) 2,2-diphenyl-1-picrylhydrazyl radical scavenging activity, (b) nitric oxide radical scavenging activity, (c) $\mathrm{Fe}^{2+}$ chelating activity, (d) superoxide radical scavenging assay, (e) reducing power assay, (f) lipid peroxidation inhibition assay

results than their corresponding pulps which are in agreement with reports available in the literature [9]. Peel extracts manifested differential expression of antioxidant capacity in different assays due to their phytoconstituents operational under different mechanism. Lemon peel showed highest activity in nitric oxide scavenging and reducing power assay while sour orange peel demonstrated maximum action against superoxide anion and ion chelating activity. Whereas in DPPH and LPO inhibition assay, peels of citron and orange showed highest activity. On the other hand, orange pulp exhibited superior antioxidant potential in all the assays studied with the exception of reducing power and superoxide anion scavenging, in which pomello and citron pulp gave the best results, respectively. Further, the results are corroborative to the quantitative assays, namely, total phenolic, flavonoids, ascorbic acid, and total antioxidants. The data therefore suggest that the extracts of Citrus are a potential source of natural antioxidants.
Nowadays, there is increasing evidence that indigenous antioxidants may be useful in preventing the deleterious consequences of oxidative stress, and there is incessant interest in the protective biochemical functions of natural antioxidants contained in spices, herbs, and medicinal plants [44]. Natural antioxidants, particularly in fruits, can be phenolic compounds (tannins, flavonoids, phenolic acids, and tocopherols), nitrogen compounds (alkaloids, chlorophyll derivatives, amino acids, and amines), or carotenoids as well as ascorbic acid $[2,49]$. The antioxidant activity of phenolics is mainly because of their redox properties, which allow them to act as reducing agents, hydrogen donors, singlet oxygen quenchers, and metal chelators [30,50]. In the present study, antioxidant activity mainly attributed to the presence of Vitamin C and phenolics. Flavonoids are most important natural phenolics. These possess broad-spectrum chemical and biological properties including radical scavenging properties [51]. Most 
polyphenols, especially flavonoids, are very effective scavengers of hydroxyl and peroxyl radical [52]. The correlation between total phenol contents and antioxidant activity has been widely studied in different foodstuffs such as fruit and vegetables [53-56]. The study of Ghafar et al. has shown a direct relation between antioxidant activity of Citrus species and phenolic contents. Ascorbic acid is highly bioavailable and is the most important water-soluble antioxidant vitamin in cells, effectively scavenging ROS. When relating the antioxidant activities of fruit juices to health and disease risk, it is important to consider the contribution of ascorbic acid in addition to that of phenolic compounds with antioxidant activity [57]

In addition to the prominent role of phenolics, the presence of other phytoconstituents, namely, alkaloids, sterols, glycosides, R-tocopherol, $\beta$-carotene, and reduced glutathione may also play a crucial role [58]. The presence of these phytochemicals has been recently considered of crucial nutritional importance in the prevention of chronic diseases such as cancer, cardiovascular disease, and diabetes [59].

Thus, the present study documents that all the five extracts of Citrus fruits commonly used in South India for various purpose either in pulp or peel form possess powerful antioxidant capacity, wherein the latter was found to be distinctly superior for the parameters assessed and are therefore potential sources of bioactive compounds and can be considered as antioxidant constituents for developing functional foods and for allied benefits.

\section{CONCLUSION}

In the present study, the results proved that the highest activity was shown by the Citrus peel extracts in most of the assays performed than that of the pulp extracts. The broad range of activity of the extracts suggests that multiple mechanisms mediated by the phytoconstituents are responsible for the antioxidant activity. The study, therefore, suggests that the Citrus fruits possess potent antioxidant activity, which might be helpful in preventing or slowing the progress of various oxidative stress-related diseases.

\section{REFERENCES}

1. Sen S, Chakraborty R, Sridhar C, Reddy YS, De B. Free radicals, antioxidants, diseases and phytomedicines: Current status and future prospect. Int J Pharm Sci Rev Res 2010;3:91-4.

2. Jamuna KS, Ramesh CK, Srinivasa TR, Raghu KL. Comparative studies on DPPH and reducing power antioxidant properties in aqueous extracts of some common fruits. J Pharm Res 2010;3(10):2378-80 .

3. Halliwell B. Antioxidants and human disease: A general introduction. Nutr Rev 1997;55:S44-9.

4. Poli G, Leonarduzzi G, Biasi F, Chiarpotto E. Oxidative stress and cell signaling. Curr Med Chem 2004;11:1163-82.

5. Abid R, Mahmood R, Rajesh KP, Swamy BE. Potential in vitro antioxidant and protective effect of Cassia fistula Linn. Fruit extracts against induced oxidative damage in human erythrocytes. Int J Pharm Pharm Sci 2014;6(9):497-505.

6. Anderson D, Phillips BJ, Tian-Wei YU, Edwards AJ, Ayesh R, Butterworth KR. Effects of Vitamin C supplementation in human volunteers with a range of cholesterol levels on biomarkers of oxygen radical-generated damage. Pure Appl Chem 2000;72:973-83.

7. Oyedepo TA. Antioxidant potential of Citrus maxima fruit juice in rats. Glob Adv Res J Med Med Sci 2012;1(5):122-6.

8. Rattan SI. Theories of biological aging: Genes, proteins, and free radicals. Free Radic Res 2006;40(12):1230-8.

9. Kumari S, Sarmah N, Handique AK. Antioxidant activities of the Unripen and ripen Citrus aurantifolia of Assam. Int J Innov Res Sci Eng Technol 2013;2(9):4811-6.

10. Ramchoun M, Harnafi H, Alem C, Benlys M, Elrhaffari L, Amrani S. Study on antioxidant and hypolipidemic effects of polyphenol rich extract from Thymus vulgaris and Lavendula multifida. Pharmacogn Res 2009;1:106-12.

11. Nagulendran K, Velavan S, Mahesh R, Begum VH. In vitro antioxidant activity and total polyphenolic content of Cyperus rotundus rhizomes. Eur J Chem 2007;4:440-9.

12. Jamuna KS, Ramesh CK, Srinivasa TR, Raghu KL. In vitro antioxidant studies in some common fruits. Int J Pharm Pharm Sci 2011;3(1):60-3.

13. Hamdan ID, Abdulla HR, Mohamed EM, El-Shazly MA. Chemical composition and biological activity of essential oils of Cleopatra mandarin (Citrus reshni) cultivated in Egypt. J Pharmacogn Phytother 2013;5(5):83-90

14. Guimarães R, Barros L, Barreira JC, Sousa MJ, Carvalho AM, Ferreira IC. Targeting excessive free radicals with peels and juices of citrus fruits: Grapefruit, lemon, lime and orange. Food Chem Toxicol 2010;48(1):99-106.

15. Jamuna KS, Ramesh CK, Mahmood R, Pallavi M, Rao SJ. Effect of different extraction methods on total phenolic content and antioxidant activities of Raphanus sativus L. Int J Bioassays 2015;4(12):4653-7.

16. Trease GE, Evans WC. A Text Book of Pharmacognosy. $11^{\text {th }}$ ed. London: Bailliere Tidall; 1978. p. 530.

17. Khandelwal KR. Practical Pharmacognosy Techniques and Experiments. $16^{\text {th }}$ ed. Pune: Nirali Prakashan; 2006. p. 149-56.

18. Kokate CK, Purohith AP, Gokhale SB. Pharmacognosy. Pune: Nirali Prakashan; 1990. p. 120.

19. Chandler SF, Dodds JH. The effect of phosphate, nitrogen and sucrose on the production of phenolics and solasidine in callus cultures of Solanum laciniatum. Plant Cell Rep 1993;2:1005-110.

20. Zhishen J, Mengcheng T, Jianming W. The determination of flavonoid contents in mulberry and their scavenging effects on superoxide radicals. Food Chem 1999;64:555-9.

21. Sadasivam S, Manickam A. Biochemical Methods. $2^{\text {nd }}$ ed. New Delhi: New Age International; 2004. p. 185-6.

22. Prieto P, Pineda M, Aguilar M. Spectrophotometric quantitation of antioxidant capacity through the formation of a phosphomolybdenum complex: Specific application to the determination of Vitamin E. Anal Biochem 1999;269(2):337-41.

23. Wong SP, Lai PL, Jen HW. Antioxidant activities of aqueous extracts of selected plants. Food Chem 2006;99:775-83.

24. Garrat DC. The Quantitative Analysis of Drugs. Vol. 3. Japan: Chapman and Hall; 1964. p. 456-8

25. Dinis TC, Madeira VM, Almeidam LM. Action of phenolic derivates (acetoaminophen, salycilate, and 5- aminosalycilate) as inhibitors of membrane lipid peroxidation and peroxyl radicals scavengers. Arch Biochem Biophys 1994;315:161-9.

26. Nishimiki M, Rao NA, Yagi K. The occurrence of super-oxide anion in the reaction of reduced phenazine methosulfate and molecular oxygen. Biochem Biophys Res Commun 1972;46:849-53.

27. Oyaizu M. Studies on products of browning reactions: Antioxidant activities of products of browning reaction prepared from glucose amine. Jpn J Nutr 1986;44:307-15.

28. Halliwell B, Guttridge JM. Free Radicals in Biology and Medicine. $2^{\text {nd }}$ ed. Japan: Scientific Societies Press; 1989

29. Gorinstein S, Huang D, Leontowicz H, Leontowicz M, Yamamoto K, Soliva-Fortuny R, et al. Determination of naringin and hesperidin in Citrus fruit by high performance liquid chromatography: The antioxidant potential of citrus fruit. Acta Chromatogr 2006;17:108-24

30. Jamuna KS, Ramesh CK, Rao SJ, Paramesha M, Mahmood R. Quantitative analysis of natural antioxidants and free radical scavenging activities of Cruciferae vegetables. Asian J Pharm Clin Res 2017;10(4):472-8

31. Ames BN, Shigenaga MK, Hagen TM. Oxidants, antioxidants, and the degenerative diseases of aging. Proc Natl Acad Sci U S A 1993;90(17):7915-22.

32. Gey KF. The antioxidant hypothesis of cardiovascular disease: Epidemiology and mechanisms. Biochem Soc Trans 1990;18(2):1041-5.

33. Ozen T. Antioxidant activity of wild edible plants in the Black Sea region of Turkey. Grasas Aceites 2010;61:86-94.

34. Barberousse H, Roiseux O, Robert C, Paquot M, Deroanne C, Blecker C. Analytical methodologies for quantification of ferulic acid and its oligomers. J Sci Food Agr 2008;88:1494-511.

35. Patra KS, Kumar KJ. Establishing correlation of therapeutic activity of a siddha formulation with its antioxidant activity-a comparative study. Int J Pharm Bio Sci 2010;1:1-8

36. Chung Y, Chien C, Teng K, Chou S. Antioxidative and mutagenic properties of Zanthoxylum ailanthoides Sieb and zucc. Food Chem 2006;97:418-25

37. Rekha C, Poornima G, Manasa M, Abhipsa V, Devi JP, Kumar HT, et al. Ascorbic acid, total phenol content and antioxidant activity of fresh juices of four ripe and unripe citrus fruits. Chem Sci Trans 2012;1(2):303-10

38. Okwu DE, Emenike IW. Nutritive value and mineral content of different varieties of citrus fruits. J Food Technol 2007;5(2):92-1054.

39. Ersus S, Cam M. Determination of organic acids, total phenolic content, 
and antioxidant capacity of sour Citrus aurantium fruits. Chem Nat Compd 2007;43(5):607-9.

40. Yuan-Chuen W, Yueh-Chueh C, Hsing-Wen H. The flavonoid, carotenoid and pectin content in peels of Citrus cultivated in Taiwan. Food Chem 2008;106:277-84.

41. Yuan-Chuen W, Yueh-Chueh C, Yu-Hua K. Quantitation of bioactive compounds in Citrus fruits cultivated in Taiwan. Food Chem 2007;102:1163-71.

42. Bocco A, Cuvelier ME, Richard H, Berset C. Antioxidant activity and phenolic composition of citrus peel and seed extracts. J Agric Food Chem 1998;4:2123-9.

43. Gorinstein S, Cvikrova M, Machackova I, Haruenkit R, Park YS, Jung ST. Characterization of antioxidant compounds in Jaffa sweeties and white grapefruits. Food Chem 2004;84:503-10.

44. Pallavi M, Ramesh CK, Krishna V, Channakeshava GH, Jamuna KS. Total phenolics and antioxidant potentials of Rotula aquatica Lour. J Appl Pharm Sci 2016;6(4):169-74.

45. Youdim KA, Dorman HJ, Deans SG. The antioxidant effectiveness of thyme oil, a tocopherol and ascorbyl palmitate on evening primrose oil oxidation. J Essent Oil Res 1999;11:643-8.

46. Frankel EN, Huang SW, Kanner J, German JB. Interfacial phenomena in the evaluation of antioxidants: Bulk oils versus emulsions. J Agric Food Chem 1994:42:1054-9.

47. Koleva II, van Beek TA, Linssen JP, de Groot A, Evstatieva LN. Screening of plant extracts for antioxidant activity: A comparative study on three testing methods. Phytochem Anal 2002;13(1):8-17.

48. Kulisic T, Radonic A, Katalinic V, Milos M. Use of different methods for testing anti-oxidative activity of oregano essential oil. Food Chem 2004;85(4):633-40.

49. Hall CA, Cuppett SL. Structure-activities of natural antioxidants. In:
Aruoma OI, Cuppett SL, editors. Antioxidant Ethodology In Vivo and In Vitro Concepts. Champaign, IL: AOCS Press; 1997. p. 2-29.

50. Evans CA, Miller NJ, Bolwell PG, Bramley PM, Pridham JB. The relative antioxidant activities of plant-derived polyphenolic flavonoids. Free Radic Res 1995;22:375-83.

51. van Acker SA, van Den Berg DJ, Tromp MN, Griffioen DH, van Bennekom WP, van der Vijgh WJ, et al. Structural aspects of antioxidant activity of flavanoids. Free Radic Biol Med 1996;20(3):331-42.

52. Manach C, Regerat F, Rexier O, Aggullo G, Demiggne C, Remesy C. Bioavailability, metabolism and physiological impact of 4-oxoflavonoids. Nutr Res 1996;16:517-44.

53. Jayaprakasha GK, Girennavar B, Patil BS. Radical scavenging activities of Rio Red grapefruits and Sour orange fruit extracts in different in vitro model systems. Bioresour Technol 2008;99(10):4484-94.

54. Ghasemi K, Ghasemi Y, Ebrahimzadeh MA. Antioxidant activity, phenol and flavonoid contents of 13 citrus species peels and tissues. Pak J Pharm Sci 2009;22(3):277-81.

55. Kedage VV, Tilak JC, Dixit GB, Devasagayam TP, Mhatre M. A study of antioxidant properties of some varieties of grapes (Vitis vinifera L.). Crit Rev Food Sci Nutr 2007;47(2):175-85

56. Klimczak I, Malecka M, Szlachta M, Gliszczynska-Swiglo A. Effect of storage on the content of polyphenols, Vitamin $\mathrm{C}$ and the antioxidant activity of orange juices. J Food Compost Anal 2007;20:313-22.

57. Gardner PT, White TA, McPhail DB, Duthie GG. The relative contributions of Vitamin C, carotenoids and phenolics to the antioxidant potential of fruit juices. Food Chem 2000;68:471-4.

58. Kaur C, Kapoor HC. Antioxidant activity and total phenolic content of some Asian vegetables. Int J Food Sci Technol 2002;37:153-61.

59. Willet WC. Diet and health: What should we eat. Science 1994;254:532-7. 